\title{
Effect of Er on the Characteristics of an Oxide Coating Prepared by Micro-Arc Oxidation on a 7075 Aluminum Alloy
}

\author{
XianJu Zhang ${ }^{*}$ Xia Luo, WuXing Ou, JunJie Huang, YangYang Li \\ School of Materials Science and Engineering, Southwest Petroleum University, Chengdu 610500, \\ China \\ *E-mail: zhangxj701@163.com
}

doi: $10.20964 / 2020.04 .51$

Received: 25 December 2019 / Accepted: 11 February 2020 / Published: 10 March 2020

\begin{abstract}
7075 Aluminum alloys with $0 \%$ (wt. $\%$ ), $0.15 \%$ and $0.30 \%$ Er were subjected to micro-arc oxidation under the same parameters. The surface morphology and the phases of the oxide coating were analyzed using SEM and XRD. The microhardness, thickness and corrosion resistance of the oxide coating were also studied. The results show that the micro-arc oxidation coating on a 7075 aluminum alloy with different Er contents is composed of the gamma- $\mathrm{Al}_{2} \mathrm{O}_{3}$ phase. With increasing Er content, the peak of the gamma- $\mathrm{Al}_{2} \mathrm{O}_{3}$ phase becomes stronger. Er enters the oxide coating in the form of $\mathrm{Al}_{17} \mathrm{Er}_{2}$, which is an unbalanced phase under micro-arc oxidation. With increasing Er content, the surface deposits become finer and more uniform, the microhole diameter decreases, and the flatness increases. As the Er content increases from $0 \%$ to $0.30 \%$, the micro-hardness and thickness of the oxide coating also increase, and then the corrosion resistance increases significantly. Consequently, the self-corrosion current density decreases from $4280.0 \mathrm{nA} / \mathrm{cm}^{2}$ to $2.405 \mathrm{nA} / \mathrm{cm}^{2}$.
\end{abstract}

Keywords: Er element, 7075 aluminum alloy, Micro-arc oxidation, Hardness, Corrosion resistance

\section{FULL TEXT}

(C) 2020 The Authors. Published by ESG (www.electrochemsci.org). This article is an open access article distributed under the terms and conditions of the Creative Commons Attribution license (http://creativecommons.org/licenses/by/4.0/). 